\title{
Is the total cardiovascular risk of hypertensive patients higher than the amount of individual risks of the involved factors?
}

\author{
Este riscul cardiovascular global al pacienţilor hipertensivi superior sumei \\ riscurilor individuale ale factorilor de risc implicaţi?
}

Gabriel Cristian BEJAN, Ana Maria Alexandra STĂNESCU, Liviu Nicolae GHILENCEA, Mihaela Adela IANCU, Constantin ŞTEFANI, Alexandra LEICA, Dumitru MATEI

Disciplina Medicina de familie, Universitatea de Medicină şi Farmacie "Carol Davila“, Bucureşti, România

\begin{abstract}
- REZUMAT
Riscul cardiovascular total al pacienților hipertensivi este dat de acțiunea concomitentă a factorilor de risc, afectarea organelor țintă (1) în cadrul hipertensiunii arteriale sau de prezența bolii cardiovasculare clinic manifeste (2).

Acțiunea concomitentă a factorilor de risc cardiovascular (3) la pacienții hipertensivi va determina un risc total superior sumei riscurilor individuale din cauza multiplicării efectului acestora în ceea ce priveşte accelerarea procesul de ateroscleroză.

Aceast efect are relevanță în special la pacienții tineri aparent sănătoşi, cu un risc absolut scăzut, şi la care prezența factorilor de risc cardiovascular la niveluri crescute poate ascunde un risc relativ înalt de boală cardiovasculară, ceea ce face ca măsurile intensive de schimbare a stilului de viață să realizeze controlul factorilor de risc în timp, cu scăderea riscului apariției bolilor cardiovasculare.

In perioada 2017-2018, am efectuat un studiu observațional retrospectiv pe 280 de pacienți dispensarizați cu hipertensiune arterială, dintre care 123 de pacienți $(43,9 \%)$ erau diagnosticați cu boală cardiovasculară aterosclerotică, constituind lotul caz, şi 157 pacienți $(56,1 \%$ ) fără boli cardiovasculare, ce au constituit lotul martor. În urma studiului, a reieşit că numărul îmbolnăvirilor întâmplate a depăşit constant numărul îmbolnăvirilor aşteptate de la asocierea a şase factori de risc cardiovascular în sus, ceea ce dovedeşte ipoteza că factorii de risc cardiovascular nu acționează separat, ci sinergic, accelerând procesul de ateroscleroză.
\end{abstract}

Cuvinte cheie: boli cardiovasculare aterosclerotice, factori de risc cardiovasculari, risc cardiovascular global

ABSTRACT

The total cardiovascular risk of hypertensive patients is due to the simultaneous action of risk factors, hypertension-mediated target organ damage or to the presence of established cardiovascular disease.

The clustering of cardiovascular risk factors which act simultaneously in patients with hypertension will cause a higher risk than the sum of individual risks due to their multiplicative effect in developing of the atherosclerosis process. 
This effect is particularly relevant in young patients apparently healthy with a low absolute risk and at who the presence of cardiovascular risk factors in high levels can hide an elevated relative risk of cardiovascular disease which makes as the intensive measures of lifestyle changes to achieve the control of risk factors over time, decreasing the risk of cardiovascular disease.

During the years 2017-2018, we performed a retrospective observational study on 280 hypertensive patients, from who 123 patients (43.9\%) got established cardiovascular disease called case and the other group called control consists of 157 patients (56.1\%) without cardiovascular disease.

The study showed that the number of cases with occurred cardiovascular disease has constantly exceeded the number of expected cases after clustering of at least six cardiovascular risk factors upwards, proving that the cardiovascular risk factors do not act individually but synergistically, which what has a multiplicative effect on process of atherosclerosis.

Keywords: atherosclerotic cardiovascular diseases, cardiovascular risk factors, total cardiovascular risk

\section{INTRODUCERE}

Bolile cardiovasculare aterosclerotice reprezintă principala cauză de mortalitate și morbiditate din lume (4).

Rolul medicului de familie ca parte a asistenței medicale primare este de a preveni bolile cardiovasculare aterosclerotice, atât prin metode ce țin de schimbarea stilului de viață al pacienților hipertensivi, cât și prin aplicarea tratamentului antihipertensiv și al factorilor de risc asociați. Algoritmul terapeutic al pacienților hipertensivi este în concordanță cu riscul cardiovascular total al acestora. Riscul cardiovascular global al pacienților hipertensivi reprezintă riscul apariției bolilor cardiovasculare ca urmare a accelerării procesului de ateroscleroză sub acțiunea concomitentă a factorilor de risc cardiovascular (5).

Riscul cardiovascular al pacienților cu boală cardiovasculară în antecedente, diabet zaharat sau care prezintă valori mult crescute ale unui singur factor de risc este un risc înalt sau foarte înalt, ceea ce impune un control strict al factorilor de risc prezenți.

Problema care se pune este la ceilalți pacienți, care nu fac parte din categoria celor de mai sus și la care riscul cardiovascular rezultă din interacțiunea multiplă a factorilor de risc prezenți (6).

Evaluarea riscului de boală cardiovasculară fatală în următorii $10 \mathrm{ani}$, la nivelul populației europene, utilizează modelul SCORE „Systematic Coronary Risk Evaluation" care ține cont de vârstă, sexul, statusul de fumător, valoarea colesterolului total și tensiunea arterială sistolică a persoanei evaluate (7).

Evaluarea riscului cardiovascular folosind riscograma SCORE este utilă în special la persoanele tinere, aparent sănătoase, dar care prezintă multipli factori de risc cardiovascular, chiar dacă nivelul acestora nu este mult crescut (8).

Acțiunea concomitentă a factorilor de risc cardiovascular la persoanele tinere poate genera un risc relativ înalt chiar dacă riscul absolut este scăzut datorită vârstei. Odată cu trecerea timpului, riscul relativ înalt va genera un risc absolut crescut, evidențiat prin creșterea incidenței bolilor cardiovasculare aterosclerotice la această categorie de pacienți.

În acest sens, măsurile intensive de schimbare a stilului de viață la pacienții tineri aflați la risc relativ înalt reprezintă conduita adecvată pentru controlul factorilor de risc în timp și scăderea riscului absolut de boli cardiovasculare aterosclerotice. Chiar dacă nu se poate obține controlul unui factor de risc, riscul total al pacientului hipertensiv poate fi scăzut prin optimizarea celorlalți factori de risc cardiovasculari prezenți și, astfel, se reduce incidența bolilor cardiovasculare aterosclerotice odată cu înaintarea în vârstă.

\section{MATERIAL ŞI METODĂ}

În perioada 2017-2018, am efectuat un studiu retrospectiv pe un lot de 280 de pacienți alcătuit din 118 bărbați (42,1 \%) și 162 femei $(57,9 \%)$, din mediul urban, dispensarizați în asistența medicală primară pentru hipertensiune arterială, la care am determinat riscul apariției bolilor cardiovasculare în concordanță cu ponderea factorilor de risc cardiovascular prezenți.

Factorii de risc cardiovascular luați în considerare au fost sexul masculin, vârsta, antecedentele de boală cardiovasculară la vârstă tânără la rudele de gradul unu sub 55 ani la bărbați și sub 65 la femei, fumatul, colesterolul total crescut, LDL-colesterolul crescut, hipertrigliceridemia, HDL-colesterolul scăzut, glicemia à jeun 
peste $100 \mathrm{mg} / \mathrm{dl}$, TAS necontrolată (9), (10), obezitatea exprimată atât prin IMC $>30 \mathrm{~kg} / \mathrm{m}^{2}$, cât și prin circumferința abdominală peste 102 $\mathrm{cm}$ la bărbați și $88 \mathrm{~cm}$ la femei, sedentarismul și consumul în exces al grăsimilor saturate.

Bolile cardiovasculare aterosclerotice diagnosticate au fost reprezentate de boala cardiacă ischemică, infarctul miocardic, procedurile de revascularizație miocardică, boala cronică de rinichi, boala arterială periferică, accidentul vascular cerebral ischemic la pacienți fără fibrilație atrială.

Criteriile de includere în studiu ale pacienților au fost reprezentate de: vârsta peste 40 ani, mediul urban, prezența în antecedente a hipertensiunii arteriale. Drept criteriu de excludere s/a folosit prezența diagnosticului fibrilației atriale în momentul producerii bolii cardiovasculare.

Cei 280 de pacienți incluși în studiu au fost împărțiți în două loturi în funcție de prezența bolilor cardiovasculare: lotul caz, format din 123 de pacienți $(43,9 \%)$ diagnosticați cu boală cardiovasculară, și lotul martor constituit din 157 pacienți $(56,1 \%)$ fără boli cardiovasculare.

Vârsta medie a pacienților studiați a fost de $66,8 \pm 9,8$ ani, extremele fiind de 44 și 90 ani.

În lotul caz, vârsta medie a fost de 68,8 \pm 9,6 ani, superioară lotului martor, unde vârsta medie a fost de 65,2 \pm 9,6 ani, această diferență fiind semnificativă statistic $p<0,01$.

\section{REZULTATE}

Am observat că la nivelul întregului lot de 280 pacienți sunt prezenți un număr total de
1.481 de factori de risc cardiovascular care determină un număr de 123 de cazuri de boală cardiovasculară, reprezentate de pacienții din lotul caz. Prin raportarea numărului de îmbolnăviri întâmplate la numărul factorilor de risc prezenți a reieșit o proporție de 0,083 îmbolnăviri întâmplate corespunzătoare unui singur factor de risc.

Am grupat în continuare pacienții din lotul caz și lotul martor în funcție de numărul de factori de risc prezenți la fiecare pacient în 13 grupe de pacienți începând cu grupa cu niciun factor de risc cardiovascular, unde întâlnim un singur pacient din lotul martor, și continuând până la grupa a 13-a, unde regăsim 4 pacienți cu 12 factori de risc din lotul caz diagnosticați cu boală cardiovasculară (Tabelul 1).

Am calculat numărul de factori de risc pentru fiecare categorie dintre cele 13 , înmulțind numărul de factori de risc corespunzător categoriei respective cu numărul de pacienți care prezintă același număr de factori de risc ca al grupei din care face parte.

De exemplu, conform tabelului 1, în categoria cu 6 factori de risc sunt un total de 40 pacienți (17 pacienți din lotul martor fără boală cardiovasculară manifestă clinic și 23 pacienți din lotul caz diagnosticați cu boală cardiovasculară clinic manifestă), la nivelul cărora acționează un număr de 240 de factori de risc (40 pacienți x 6 factori de risc).

Numărul îmbolnăvirilor așteptate I-am calculat înmulțind numărul de factori de risc calculat precum am arătat mai sus pe fiecare dintre cele

TABELUL 1. Distribuția numărului de îmbolnăviri aşteptate pe grupele de factori de risc cardiovascular în funcție de numărul factorilor de risc implicați (11)

\begin{tabular}{|c|c|c|c|c|c|}
\hline $\begin{array}{l}\text { Categorie } \\
\text { Factori de risc cardiovascular }\end{array}$ & Lotul martor & Lotul caz & Total pacienți & $\begin{array}{c}\text { Număr total } \\
\text { factori de risc } \\
\text { cardiovascular }\end{array}$ & $\begin{array}{l}\text { Îmbolnăviri } \\
\text { așteptate }\end{array}$ \\
\hline 0 Factori de risc $\mathrm{CV}$ & 1 & 0 & 1 & 0 & 0 \\
\hline 1 Factor de risc CV & 12 & 0 & 12 & 12 & 1 \\
\hline 2 Factori de risc $\mathrm{CV}$ & 48 & 1 & 49 & 98 & 8,13 \\
\hline 3 Factori de risc $\mathrm{CV}$ & 21 & 7 & 28 & 84 & 6,97 \\
\hline 4 Factori de risc $\mathrm{CV}$ & 14 & 9 & 23 & 92 & 7,64 \\
\hline 5 Factori de risc $\mathrm{CV}$ & 24 & 13 & 37 & 185 & 15,36 \\
\hline 6 Factori de risc $\mathrm{CV}$ & 17 & 23 & 40 & 240 & 19,92 \\
\hline 7 Factori de risc CV & 8 & 18 & 26 & 182 & 15,11 \\
\hline 8 Factori de risc $\mathrm{CV}$ & 6 & 13 & 19 & 152 & 12,62 \\
\hline 9 Factori de risc $\mathrm{CV}$ & 4 & 21 & 25 & 225 & 18,68 \\
\hline 10 Factori de risc CV & 2 & 11 & 13 & 130 & 10,79 \\
\hline 11 Factori de risc CV & 0 & 3 & 3 & 33 & 2,74 \\
\hline 12 Factori de risc $\mathrm{CV}$ & 0 & 4 & 4 & 48 & 3,98 \\
\hline
\end{tabular}




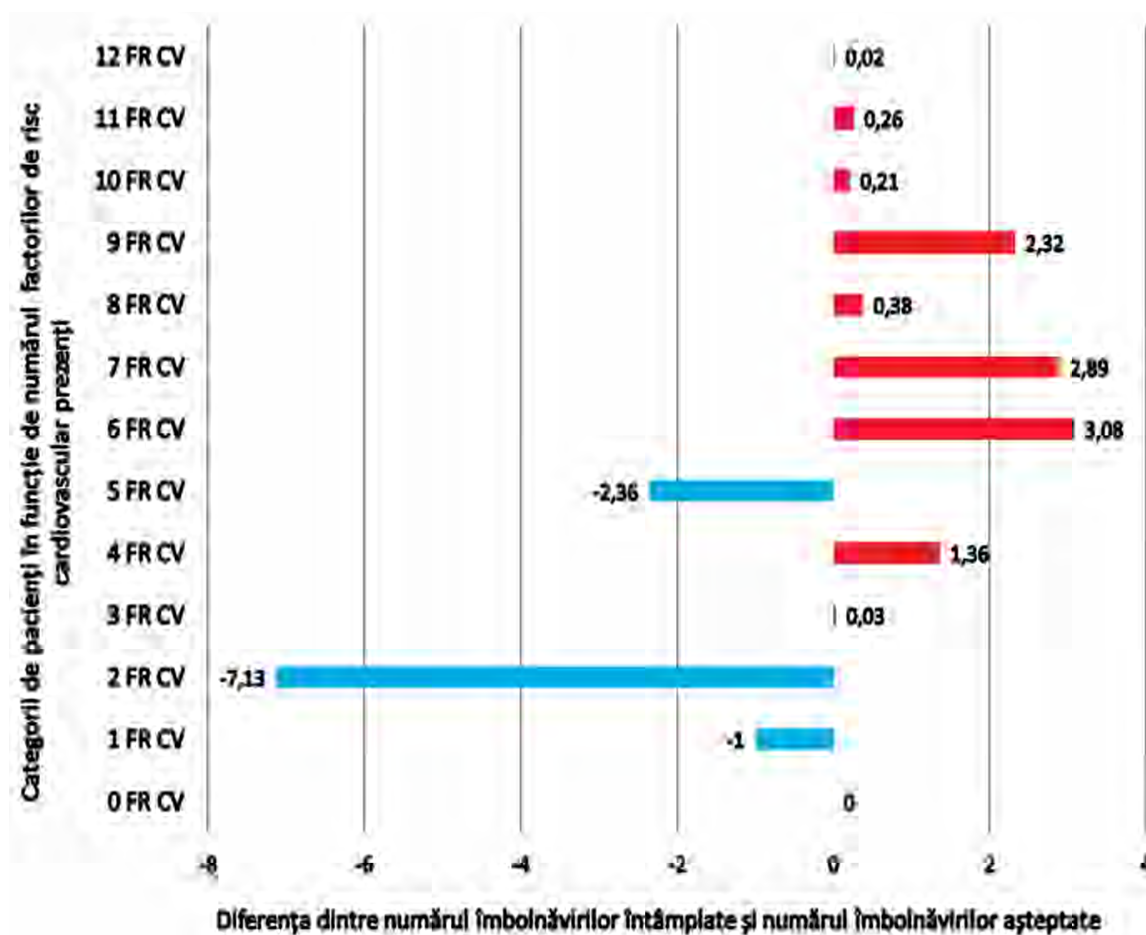

FIGURA 1. Distributia diferenței dintre numărul îmbolnăvirilor întâmplate şi numărul îmbolnăvirilor assteptate pe categoriile pacienți în funcție de numărul factorilor de risc cardiovascular prezenți (12)
13 grupe de pacienți cu 0,083 îmbolnăviri / 1 factor de risc.

De exemplu, la categoria de pacienți cu 6 factori de risc a reieșit un număr de 19,92 îmbolnăviri așteptate conform algoritmului: 240 factori de risc x 0,083 îmbolnăviri / 1 factor de risc.

Lotul caz alcătuit din 123 de pacienți diagnosticați cu boală cardiovasculară a reprezentat numărul îmbolnăvirilor întâmplate.

Se observă că, de la grupul de pacienți cu 6 factori de risc cardiovascular în sus, numărul îmbolnăvirilor întâmplate I-a depățit pe cel al îmbolnăvirilor așteptate, astfel că putem concluziona că acțiunea a cel puțin 6 factori de risc determină un efect (îmbolnăviri întâmplate) mai puternic decât suma acțiunilor fiecărui factor de risc în parte (îmbolnăviri așteptate) (vezi Fig. 1).

\section{CONCLUZII}

În cazul celor 280 de pacienți dispensarizați în asistența medicală primară pentru hipertensiune arterială, numărul îmbolnăvirilor întâmplate l-a depășit în mod constant pe cel al îmbolnăvirilor așteptate de la asocierea a cel puțin 6 factori de risc cardiovascular, ceea ce dovedește că riscul cumulat al factorilor de risc îl depășeste pe cel al sumei riscurilor fiecărui factor de risc în parte.

Acest efect apare ca urmare a acțiunii concomitente și complementare a factorilor de risc, ceea ce va avea drept rezultat accelerarea procesului de ateroscleroză într-o mai mare măsură decât suma acțiunilor fiecărui factor de risc în parte.

Această observație are consecințe practice în special la pacienții tineri aparent sănătoși, dar cu multipli factori de risc cardiovascular, care, astfel, pot ascunde un risc relativ ridicat în ciuda vârstei care determină un risc absolut scăzut.

Aplicarea măsurilor intensive în ceea ce privește modificarea stilului de viață la această categorie de pacienți are efecte favorabile în timp, scăzând incidența bolilor cardiovasculare, adică transformarea riscului relativ înalt într-un risc absolut înalt odată cu trecerea timpului.

\section{Mențiune}

Toți autorii au contribuit în mod egal la elaborarea acestei lucrări. 


\section{BIBLIOGRAFIE}

1. Sehestedt T, Jeppesen J, Hansen TW, Wachtell K, Ibsen H, Torp-Pedersen C, Hildebrandt $\mathrm{P}$, Olsen MH. Risk prediction is improved by adding markers of subclinical organ damage to SCORE. Eur Heart J 2010;31:883-891.

2. Piepoli MF, Hoes AW, Catapano AL, Graham I, Lochen ML, Redon J, Verschuren WMM, Binno $S$ et al. ESC Scientific Document Group. 2016 European Guidelines on cardiovascular disease prevention in clinical practice: The Sixth Joint Task Force of the European Society of Cardiology and Other Societies on Cardiovascular Disease Prevention in Clinical Practice (constituted by representatives of 10 societies and by invited experts)Developed with the special contribution of the European Association for Cardiovascular Prevention \& Rehabilitation (EACPR). Eur Heart J 2016;37:2315-2381.

3. Bhatt DL, Steg PG, Ohman EM, Hirsch AT, Ikeda Y, Mas JL, Goto S, Liau CS, Richard AJ, Rother J, Wilson PW. REACH Registry Investigators. International prevalence, recognition, and treatment of cardiovascular risk factors in outpatients with atherothrombosis. JAMA 2006;295:180189.
4. European Heart Network. European Cardiovascular Disease Statistics. 2008 edition.

5. Berry JD, Dyer A, Cai X, Garside DB, Ning $\mathrm{H}$, Thomas A, Greenland P, Van Horn L, Tracy RP, Lloyd-Jones DM. Lifetime risks of cardiovascular disease. N Engl J Med 2012;366:321-329

6. Cooney MT, Dudina AL, Graham IM. Value and limitations of existing scores for the assessment of cardiovascular risk: A review for clinicians. J Am Coll Cardiol 2009;54:1209-1227.

7. Conroy RM, Pyorala K, Fitzgerald AP, Sans $S$, Menotti A, De Backer $G$ et al. Estimation oft en-year risk of fatal cardiovascular disease in Europe: the SCORE project. Eur Heart J 2003; 24:987-1003.

8. Piepoli MF, Hoes AW, Brotons C, Deaton C, Hall MS, Perk J, Richter DJ, Sattar N, Binno $S$ et al. ESC Scientific Document Group. 2016 European Guidelines on cardiovascular disease prevention in clinical practice: The Sixth Joint Task Force of the European Society of Cardiology and Other Societies on Cardiovascular Disease Prevention in Clinical Practice (constituted by representatives of 10 societies and by invited experts)Developed with the special contribution of the European Association for Cardiovascular Prevention \& Rehabilitation (EACPR). Eur Heart J 2016;37:2315-2381.

9. Vishram JK, Borglykke A, Andreasen $\mathrm{AH}$, Jeppesen J, Ibsen H, Jorgensen T, Broda G, Palmieri L, Giampaoli S, Donfrancesco C, Kee F, Mancia G, Cesana G, Kuulasmaa K, Sans S, Olsen MH. MORGAM Project. Impact of age on the importance of systolic and diastolic blood pressures for stroke risk: The MOnica, Risk, Genetics, Archiving, and Monograph (MORGAM) project. Hypertension 2012;60:1117-1123.

10. Forouzanfar MH, Liu P, Roth GA, Ng M, Biryukov $S$ et al. Global burden of hypertension and systolic blood pressure of at least 110 to $115 \mathrm{~mm} \mathrm{Hg}, 1990-2015$. JAMA 2017;317:165-182.

11. Lucrare licenţă: Evaluarea riscului cardiovascular global la pacienţii hipertensivi. Leica A. 2018 pagina 58

12. Lucrare licenţă: Evaluarea riscului cardiovascular global la pacienţii hipertensivi. Leica A. 2018 pagina 62 